\title{
Effect of ultrasound power on extraction kinetic model, and physicochemical and structural characteristics of collagen from chicken lung
}

Ye Zou' ${ }^{1}$, Heng Yang ${ }^{1}$, Xinxiao Zhang ${ }^{1}$, Pingping $X^{2}{ }^{2}$, Di Jiang ${ }^{2}$, Muhan Zhang ${ }^{1}$, Weimin $X^{{ }^{1 *}}$ and Daoying Wang ${ }^{1 *}$ (D)

\begin{abstract}
The effects of ultrasound power on extraction kinetic model, and physicochemical and structural characteristics of collagen from chicken lung were studied. Ultrasound power caused a significant increase in extraction rate and equilibrium concentration, with the maximum extraction yield $(31.25 \%)$ at $150 \mathrm{~W}$. The experimental data were consistent with the predicted ones in this empirical equation, in which the percentage error differences was $0.026-4.159 \%$. Besides, ultrasound treatment did not affect their triplehelical structure. The thermal stability of pepsin-soluble collagen by ultrasound pre-treatment (UPSC) was higher, due to the higher imino acid content (20.76\%). UPSC also exhibited better solubility and fibril forming capacity. Overall, the kinetic model of UPSC from chicken lung could serve the purpose of obtaining collagen, which displayed a potential alternative source to mammal collagens for application in food, biomaterials and biomedical fields.
\end{abstract}

Keywords: Extraction kinetics, Chicken lung, Pepsin-soluble collagen, Ultrasound pretreatment

\section{Introduction}

According to Food and Agriculture Organization of the United Nations (FAO 2018) statistics, the world's chicken production in 2018 was about 97.8 million tons (of which China contributed $\sim 11.7$ million tons). Huge amounts of chicken by-products are produced due to rapid increase in the total production. The resultant by-products account for up to $\sim 50 \%$ of the chicken weight and they are currently used partially as animal feed stuffs, pet attractant and crop fertilizer, resulting in serious environmental pollution and economic loss. Therefore, better and full utilization of these by-products is becoming urgent.

Collagen is an abundant component of extracellular matrix and its unique triple helix structure makes it stable in molecular structure. Collagen has low

\footnotetext{
* Correspondence: weiminxu2002@aliyun.com; daoyingwang@yahoo.com

${ }^{1}$ Institute of Agricultural Products Processing, Jiangsu Academy of

Agricultural Sciences, Nanjing 210014, People's Republic of China

Full list of author information is available at the end of the article
}

immunogenicity and excellent biocompatibility, hence it has been used in healthy food, packaging material, biomedical material, medical and cosmetic fields (Pal \& Suresh 2016). More and more studies have focused on functional properties of collagen, especially those from the skin and bones of aquatic species compared to those from cow and pig (regional religious issues) (Bhagwat \& Dandge 2016; Jana et al. 2016; Kobayashi et al. 2016), as they are important sources of easily soluble collagen. However, due to low thermal stability of aquatic collagen, it is urgent to find collagens with high thermal stability in the biomaterial application fields. Animal lungs are abundant in collagen and chicken lungs are basically donated to farmers as animal feed for foxes and minks or discarded, resulting in a huge waste of by-product resources. The results of our previous study showed that chicken lungs contain a high amount of collagen $(\sim 30 \%$, dry weight). However, little is known about

(c) The Author(s). 2020 Open Access This article is distributed under the terms of the Creative Commons Attribution 4.0 International License (http://creativecommons.org/licenses/by/4.0/), which permits unrestricted use, distribution, and reproduction in any medium, provided you give appropriate credit to the original author(s) and the source, provide a link to the Creative Commons license, and indicate if changes were made. The Creative Commons Public Domain Dedication waiver (http://creativecommons.org/publicdomain/zero/1.0/) applies to the data made available in this article, unless otherwise stated. 
the extraction and physicochemical properties of collagen from chicken lung.

Extraction of collagen is solvent/raw material dependant process, known as leaching. Ultrasound pretreatment has emerged as a potential approach to extract substances from raw materials and has been certified to be an effective means to reduce processing time, energy, and chemical reagent consumption (Dahmoune et al. 2014). Furthermore, from an engineering view point, kinetic mathematical model is a meaningful tool, which greatly promotes process design, optimization, simulation, predetermination and manipulation (Bucić-Kojić et al. 2007; Saavedra et al. 2013). Therefore, in the process of collagen isolation, the extraction kinetic model of pepsin-soluble collagen from ultrasound pretreated (UPSC) chicken lung is essential and meaningful for reactor design. Additionally, the physicochemical and structural characteristics of UPSC were also investigated in this contribution.

\section{Materials and methods}

\section{Materials and chemical reagents}

The fat from chicken lungs was removed manually and the extracted lungs were then washed from the internal blood with tap water two times and then once with deionized water. The lungs were then cut into slices $(\sim 1.0 \times 0.5 \mathrm{~cm})$, stirred in a high-speed mixer until they were well homogenized. The mixture was then kept at $-20^{\circ} \mathrm{C}$ according to the method described previously by Zou et al. (2017). Pepsin (4000 $\mathrm{U} \mathrm{mg}^{-1}$, dry matter), the standard ${ }_{\mathrm{L}}$-hydroxyproline $\left({ }_{L^{-}}(\mathrm{OH}) \mathrm{C}_{4} \mathrm{H}_{7} \mathrm{~N}(\mathrm{COOH})\right.$ ), and dimethylaminobenzaldehyde $\left(\left(\mathrm{CH}_{3}\right)_{2} \mathrm{NC}_{6} \mathrm{H}_{4} \mathrm{CHO}\right)$ were bought from SigmaAldrich (St. Louis, MO, USA). Sodium dodecyl sulfate (SDS) and coomassie brilliant blue R-250 were purchased from Yuanye Laboratories Inc. (Shanghai, China). All the other reagents used in the experiment were of analytical grade.

\section{Preparation of chicken lung}

Chicken lungs were immersed in $\mathrm{NaCl}$ solution $(20 \%$, w $\left.\mathrm{v}^{-1}\right)$ at 1:20 $\left(\mathrm{w} \mathrm{v}^{-1}\right)$ and stirred for $8 \mathrm{~h}$ using a magnetic stirrer at $20^{\circ} \mathrm{C}$. The extraction mixture was subsequently centrifuged and the precipitate was immersed in $0.5 \mathrm{M}$ $\mathrm{Na}_{2} \mathrm{CO}_{3}$ solution with $1: 20\left(\mathrm{w} \mathrm{v}^{-1}\right)$ for $24 \mathrm{~h}$. The $\mathrm{Na}_{2} \mathrm{CO}_{3}$ solution was changed every $8 \mathrm{~h}$. The minerals of chicken lung were removed by using $\mathrm{Na}_{2}$-EDTA solution $(0.3 \mathrm{M}, \mathrm{pH} 7.4)$ at a ratio of $1: 20\left(\mathrm{w} \mathrm{v}^{-1}\right)$ for $24 \mathrm{~h}$ with agitation. The solution of $\mathrm{Na}_{2}$-EDTA $(0.3 \mathrm{M}, \mathrm{pH}$ 7.4) was also renewed every $8 \mathrm{~h}$. The sediment from centrifugation was immersed in isopropyl alcohol solution $\left(10 \%, \mathrm{v} \mathrm{v}^{-1}\right)$ to fat removal then washed several times with distilled water until samples reached a $\mathrm{pH}$ of 7 .
Finally, the pretreated chicken lungs were kept at $40^{\circ} \mathrm{C}$ for further use.

\section{Extraction and purification of collagen Traditional extraction and purification of pepsin-soluble collagen (PSC)}

Extraction and purification of PSC was performed according to the description of Chen et al. (2016) with slight modifications. PSC was extracted from the above operation steps with acetic acid solution $\left(0.5 \mathrm{M}, 1,20, \mathrm{w} \mathrm{v}^{-1}\right)$ containing pepsin (2000 $\mathrm{Ug}^{-1}$ substrate) for $24 \mathrm{~h}$. Subsequently, the supernatant of samples was collected by centrifugation. The residue of samples was extracted again using the same procedure. The obtained supernatant after centrifugation was added with $\mathrm{NaCl}$ to do a salting-out process $(2.5 \mathrm{M}$ and $1.0 \mathrm{M})$ for $12 \mathrm{~h}$. The precipitate from salting-out process by centrifugation was re-dissolved in acetic acid solution with 1:10 $\left(0.5 \mathrm{M}, \mathrm{w} \mathrm{v}^{-1}\right)$ and then dialyzed in $0.1 \mathrm{M}$ acetic acid solution $\left(1,25, \mathrm{w} \mathrm{v}^{-1}\right)$, followed by double distilled water. PSC was lyophilized and then kept at $-20^{\circ} \mathrm{C}$ for further use.

\section{Extraction and purification of UPSC from chicken lung}

The sample was extracted with acetic acid solution $(0.5$ $\mathrm{M}, 1: 20, \mathrm{w} \mathrm{v}^{-1}$ ) in an ultrasound processor (SCIENTZIID, Ningbo Xinzhi ultrasonic technology Co., Ltd., Zhejiang, China), where the flat tip probe immersion depth was around $1.0 \sim 2.0 \mathrm{~cm}$. The operating mode was set as a pulsed on-time $2 \mathrm{~s}$ and off-time $3 \mathrm{~s}$. The frequency and power of ultrasound were $24 \mathrm{kHz}$ and $150 \mathrm{~W}$, respectively. The extraction lasted $5 \mathrm{~min}$. The temperature of cooling water passing steel jacket was set at $20^{\circ} \mathrm{C}$ to avoid heating effects. Then pepsin $\left(2000 \mathrm{U} \mathrm{g}^{-1}\right.$ substrate) was added into the ultrasound pre-treatment samples. The next step was performed as given in the above section. UPSC was lyophilized and kept at $-20^{\circ} \mathrm{C}$ for further determination.

\section{Yield of collagen powder}

The computational formula for the yield of PSC/UPSC was expressed as:

$$
\% \text { Yield }=\frac{m_{P S C} / \text { UPSC }}{m} \times 100
$$

where $m_{P S C / U P S C}$ was the weight of collagen from chicken lung (dry weight after miscellaneous (heteroproteins, fats and mineral) removal) and $m$ was the weight of chicken lung (dry weight after miscellaneous removal).

\section{Kinetic model}

A second-order model is usually employed to investigate kinetic model for solvent/raw material extraction. The second-order model could offer a representation of 
extracting, as obvious from its important application in modeling extraction (Ho et al. 2005; Qu et al. 2010; Tao et al. 2014). The dynamic parameters in the secondorder kinetic model could be illuminated. This model has also been derived to investigate the chicken lung collagen. The second-order kinetic model of extraction is as follows:

$$
\frac{d C t}{d t}=k\left(C_{e}-C_{t}\right)^{2}
$$

where $C_{t}$ is the collagen concentration $\left(\mathrm{mg} \mathrm{mL}^{-1}\right)$ at time $t, C_{e}$ is the equilibrium concentration of collagen $\left(\mathrm{mg} \mathrm{mL}^{-1}\right)$ and $k$ is the second order rate constant $(\mathrm{mL}$ $\left.\mathrm{mg}^{-1} \min ^{-1}\right)$.

Solving Eq. (2) with the boundary conditions as $\left.C_{t}\right|_{t=}$ $0=0$ and $\left.C_{t}\right|_{t=t}=C_{t}$ gives

$$
C_{t}=\frac{C_{e}^{t} k t}{1+C_{e} k t}
$$

Eq. (3) can be rewritten as Eq. (4) and subsequently reduced to Eq. (5) as follows

$$
\frac{t}{C_{t}}=\frac{1}{k C_{e}^{2}}+\frac{t}{C_{e}}
$$

when $t$ approaches 0 , the initial collagen extraction rate, $h\left(\mathrm{mg} \mathrm{mL}^{-1} \mathrm{~min}^{-1}\right)$, can be written as:

$$
\begin{aligned}
& h=k C_{e}^{2} \\
& \frac{t}{C_{t}}=\frac{1}{h}+\frac{t}{C_{e}}
\end{aligned}
$$

A plot of $t C_{t}^{-1}$ vs $t$ can be drawn to determine $C_{e}, k$ and $h$.

After rearranging Eq. (6), $C_{t}$ can therefore be expressed as:

$$
C_{t}=\frac{t}{\left(\frac{1}{h}\right)+\left(\frac{t}{C_{e}}\right)}
$$

\section{Sodium dodecyl sulfate-polyacrylamide gel electrophoresis (SDS-PAGE)}

SDS-PAGE was used to analyze the distribution of collagen subunits. The concentrations of polyacrylamide stacking gels and separating gels were 4 and $12 \%$, respectively, and the sample wells were loaded with $25 \mu \mathrm{L}$. After dyeing and decolorizing, the electrophoretic bands were analyzed.

\section{Fourier transform infrared (FT-IR) spectroscopy}

The FT-IR spectrum of collagen was acquired in a FTIR spectrometer (Cary 600 Series, Agilent Technologies Inc., USA), with wavelength range from 4000 to 650 $\mathrm{cm}^{-1}$ and 32 scans. Two milligrams of the freeze-dried collagen powder were used and the measuring resolution was $4 \mathrm{~cm}^{-1}$.

\section{Amino acid composition}

Five milligrams of sample power were hydrolyzed overnight in $\mathrm{HCl}$ solution $(6 \mathrm{M})$ at $110-115^{\circ} \mathrm{C}$. The amino acid composition was measured by automatic amino acid analyzer (Hitachi L8800, Hitachi High-Technologies Co., Tokyo, Japan). The profile of amino acid was presented as the ratio of the individual amino acid to total amino acids. The results were reported as grams of amino acid per $100 \mathrm{~g}$ freeze-dried lyophilized sample, respectively. The percentage of tryptophan was not determined.

\section{Determination of viscosity}

Denaturation temperature $\left(T_{d}\right)$ was determined by the method presented by Yang et al. (2016). Firstly, the Ostwald's viscometer was filled with $1.0 \mathrm{~g} \mathrm{~L}^{-1}$ collagen solution in acetic acid $(0.1 \mathrm{M})$. The temperature increased from 10 to $50^{\circ} \mathrm{C}$ and the interval was $5{ }^{\circ} \mathrm{C}$. Every temperature was kept for $30 \mathrm{~min}$ and the viscosities were determined. The collagen $T_{d}$ was considered as the mid-point of the linear portion, which was acquired by plotting fractional viscosity against temperatures. At least three measurements were carried on at each temperature.

\section{Differential scanning calorimetry (DSC)}

The sample melting temperature $\left(T_{m}\right)$ was analyzed by DSC (Q20, instruments, New Castle, DE, USA). Samples of $8.0 \mathrm{mg}$ were heated from 20 to $170{ }^{\circ} \mathrm{C}$ at a rate of $15{ }^{\circ} \mathrm{C} \mathrm{min}^{-1} . T_{m}$ was defined as the temperature of endothermic peak. An empty pan was used as reference. The data of $T_{m}$ for PSC and UPSC were obtained as the mean value of at least three determines.

\section{Scanning electron microscopy (SEM)}

The surface microstructure of the lyophilized PSC and UPSC powders were observed using a scanning electron microscope (EVO-LS10, ZEISSE, Baden Wurttemberg, Germany) with $10.0 \mathrm{kV}$ of an accelerating voltage. Lyophilized samples were coated in an argon atmosphere using a gold/palladium alloy coater. The images of collagens were observed at 50 and $100 \times$ magnification.

\section{Solubility}

The influences of $\mathrm{pH}$ and $\mathrm{NaCl}$ on the collagen solubility were studied based on the method of Yu et al. (2014). The collagen samples were dissolved in acetic acid solution $(0.5 \mathrm{M})$ and mixed at $4{ }^{\circ} \mathrm{C}$ to get a $2.5 \mathrm{mg} \mathrm{mL}^{-1}$ solution. The $\mathrm{pH}$ of the sample solutions was adjusted to 2-10 with either $\mathrm{HCl}(1.0 \mathrm{M})$ or $\mathrm{NaOH}(1.0 \mathrm{M})$, 
respectively. Distilled water was used to adjust the solution volume to $10 \mathrm{~mL}$. The solutions were then centrifuged at $4{ }^{\circ} \mathrm{C}(10,000 \mathrm{~g}, 15 \mathrm{~min})$. To study the effect of $\mathrm{NaCl}, 0,2,4,6,8,10$ and $12 \%$ of $\mathrm{NaCl}$ solutions were applied. The supernatants after centrifugation from the above solutions were used for determination of solubility of samples using the Kjeldahl method.

\section{Protein analysis by NanoLC-ESI-MS/MS}

The protein bands $\alpha_{1}$ and $\alpha_{2}$ on the gels were excised manually for NanoLC-ESI-MS/MS analysis following the method of Kang et al. (2017). In brief, each sample was firstly reduced by DTT and all cysteine residues alkylated by iodoacetamide and cleaned by desalting columns or ethanol precipitation. The sample was then digested with sequencing grade modified trypsin (Promega) in $100 \mathrm{mM}$ of ammonium bicarbonate ( $\mathrm{pH}$ 8.5). A dissolved peptide was determined by a NanoLC-ESI-MS/ MS system.

The particle size of the $C_{18}$ was $3 \mu \mathrm{M}$ and the pore size was $300 \ddot{A}$. Typical sample injection volume was $3 \mu \mathrm{L}$. All measured MS results were used to retrieve the most recent non-redundant protein database (NR database, NCBI) with ProtTech's ProtQuest software suite to obtain the information of collagen samples. The output from the database search was manually validated before reporting. The label-free quantitation method was used for the measurement of relative abundance of protein in each excised protein band.

\section{Statistical analysis}

Data were reported as mean $\pm \mathrm{SD}$. The results were analyzed with one-way analysis of variance (ANOVA) using SPSS 19.0. Significant differences were analyzed using the least significant difference (LSD) test. The significance was established at $P<0.05$.

\section{Results and discussion}

\section{Development of collagen extraction kinetic model}

The appropriate ultrasonic power in collagen extraction from the chicken lung with ultrasound pretreatment can be identified through regression analysis. It was performed to establish empirical correlations for prediction of ' $h$ ' and ' $C e$ ', as well as the kinetic model. The results of $C_{t} / t$ and $t$ were obtained from the slope and intercept of Fig. 1 at a given liquid to material ratio of $20 \mathrm{~mL} \mathrm{~g}^{-1}$ and pepsin $\left(2000 \mathrm{U} \mathrm{g}^{-1}\right)$. The data showed that the improvement in UPSC yield was obtained when higher ultrasonic power (P) was operated in the extraction process and the highest $C_{e}$ was achieved at $150 \mathrm{~W}$. However, a reverse trend was obtained at the treatment 200 W. This was due to the excessive ultrasonic power that might depress the solubility or destroy collagen structure in the extraction process. Meanwhile, the different

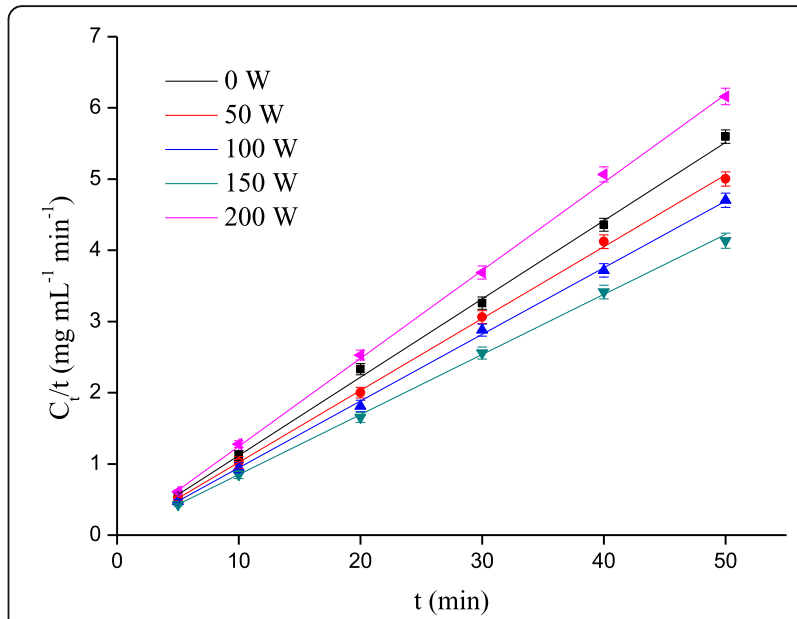

Fig. 1 Effect of extraction time on the concentration of collagen $\left(\mathrm{mg} \mathrm{mL}^{-1}\right)$ at any time $t$ during ultrasound power carried out at liquid to solid ratio of $20 \mathrm{~mL} \mathrm{~g}^{-1}$ and pepsin $\left(2000 \mathrm{U} \mathrm{g}^{-1}\right)$

ultrasonic power of the extraction rate constant, $k$, initial extraction rate, $h$, and equilibrium concentration, $C_{e}$, are presented in Table 1 . Therefore, the changes of kinetic parameters with ultrasonic power were represented by polynomial order polynomial functions as:

$$
\begin{aligned}
C_{e(P)}= & 9.07+0.0486 P-0.00116 P^{2} \\
& +1.215 \mathrm{E}^{-5} P^{3}-3.853 \mathrm{E}^{-8} P^{4} \\
h_{(P)}= & 54.3+1.570 P-0.0366 P^{2} \\
& +3.858 \mathrm{E}^{-4} P^{3}-1.186 \mathrm{E}^{-6} P^{4} \\
k_{(P)}= & 0.668+0.00281 P+5.143 \mathrm{E}^{-6} P^{2}
\end{aligned}
$$

Therefore, $C_{t}$ based upon ultrasonic power is obtained by substituting the above equations in Eq. (7) as:

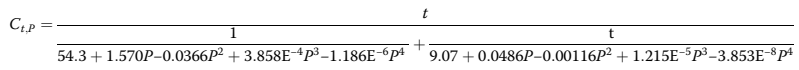

The above equation could be applied to predict a collagen yield from chicken lung under various ultrasonic powers. The obtained low errors ranges were 0.026$4.159 \%$ from the satisfactorily fitted experimental data. Therefore, the developed models could be applied to predict the extraction performances.

\section{SDS-page}

SDS-PAGE patterns of collagens from two extractions are shown in Fig. 2. Both PSC and UPSC were composed of $\alpha_{1}$ chain and $\alpha_{2}$ chain with approximate molecular weights below $130 \mathrm{kDa}$. The band intensities of $\alpha_{1}$-chain are twice higher than that of $\alpha_{2}$-chain in this pattern. The higher molecular weight components, particularly 
Table 1 Extraction rate constant, initial extraction rate and equilibrium concentration for different process conditions of ultrasonic extraction

\begin{tabular}{llll}
\hline Ultrasonic processing $(\mathrm{W})$ & $\begin{array}{l}\text { Initial extraction rate, } \\
h\left(\mathrm{mg} \mathrm{mL}^{-1} \mathrm{~min}^{-1}\right)\end{array}$ & $\begin{array}{l}\text { Equilibrium concentration of } \\
\text { collagen, } C_{e}(\mathrm{mg} \mathrm{mL})^{-1}\end{array}$ & $\begin{array}{l}\text { Extraction rate constant, } \\
k\left(\mathrm{~mL} \mathrm{mg} \mathrm{min}^{-1}\right)\end{array}$ \\
\hline 0 & 29.77 & 4.97 & 0.66 \\
50 & 45.04 & 5.42 & 0.84 \\
100 & 61.79 & 5.85 & 0.99 \\
150 & 92.38 & 6.49 & 1.20 \\
200 & 51.67 & 4.43 & 1.44 \\
\hline
\end{tabular}

$\beta$-chains (dimmers of the $\alpha$-chains), with a molecular weight of $200 \mathrm{kDa}$, were also present in our study. These SDS-PAGE patterns were similar to type I collagen triple helix from chicken bone (Oechsle et al. 2016). However, there were no $\gamma$-chains (trimers of the $\alpha$-chains) in UPSC compared with PSC, implying that ultrasound could promote protein degradation in the extraction process. Therefore, SDS-PAGE patterns clearly demonstrated that the collagen acquired from the chicken lung was pure.

\section{Fourier transform infrared (FTIR) spectroscopy}

FTIR spectrum provides special information on molecular structure, which allows investigation of the physicochemical property of proteins and collagen (Petibois \& Déléris 2006). Amide A band observed at $\sim 3410-3490 \mathrm{~cm}^{-1}$ is generally caused by $\mathrm{NH}$ stretching vibration. When the $\mathrm{NH}$ stretching of a protein or collagen contains a hydrogen bond, the absorption peak of amide $\mathrm{A}$ is shifted to

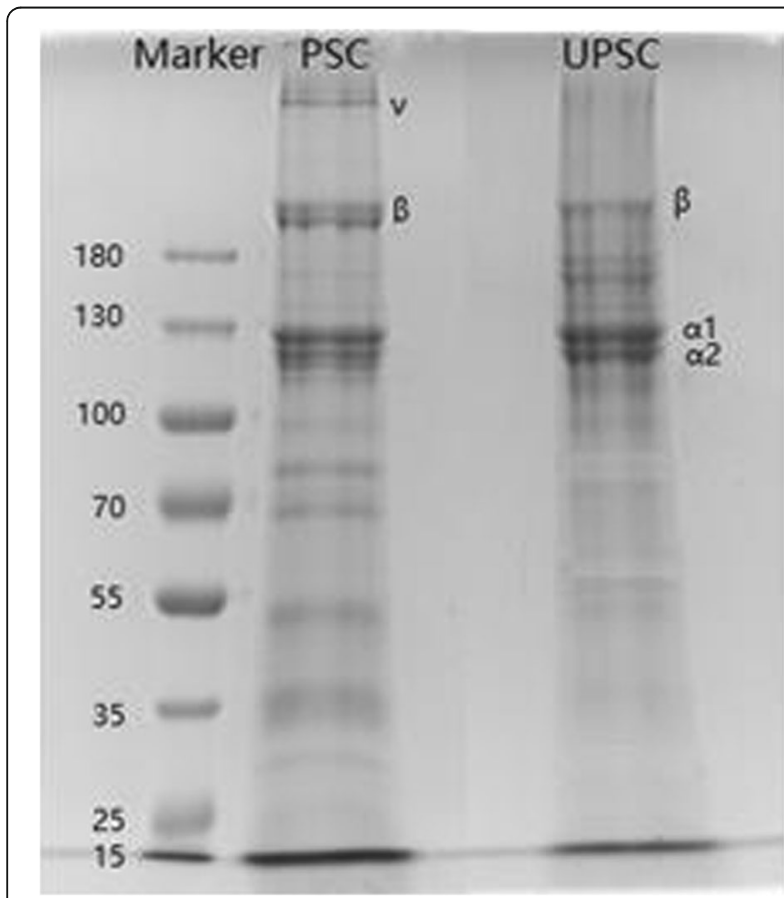

Fig. 2 Sodium dodecyl sulfate-polyacrylamide gel electrophoresis (SDS-PAGE) patterns of PSC and UPSC from chicken lung lower frequencies; usually around $3300 \mathrm{~cm}^{-1}$ (Wang et al. 2014). The amide A band of PSC was found at $3319 \mathrm{~cm}^{-1}$ and had resemblance to that of UPSC from chicken lung in Fig. $3\left(3316 \mathrm{~cm}^{-1}\right)$. Amide B is related to the asymmetric stretching vibration of $\mathrm{CH}$ alkyl chain, as well as $\mathrm{NH}_{3}{ }^{+}$ and has an absorption peak around $2850-2950 \mathrm{~cm}^{-1}$ (Peticolas 1979). In this study, as shown in Fig. 3, the amide B bands of PSC and UPSC occurred at 2891 and $2889 \mathrm{~cm}^{-1}$, respectively.

The vibrational frequencies of amides I, II, and III bands are well-known to be directly linked to the shape of a side group polypeptide. Amide I, characterized in the range of $1600-1700 \mathrm{~cm}^{-1}$, is the most important element to determine the secondary structure of a collagen (Chuaychan et al. 2015; Huang et al. 2016). The amide I band of PSC and UPSC appeared at 1673 and $1675 \mathrm{~cm}^{-1}$, respectively, similar to the results of skin collagen of catla (Catla catla) and rohu (Labeo rohita) (Pal, Nidheesh \& Suresh 2015). The amide II is generally associated with $\mathrm{N}-\mathrm{H}$ inplane bend as well as $\mathrm{C}-\mathrm{N}$ stretching vibrations. The amide II of PSC and UPSC were present at 1582 and $1579 \mathrm{~cm}^{-1}$, respectively. The amide III is responsible for $\mathrm{C}-\mathrm{N}$ stretching and $\mathrm{N}-\mathrm{H}$ from amide linkages, and is located in the collagen structure (Alfaro et al. 2014). Amide III bands of PSC and UPSC were located at the same

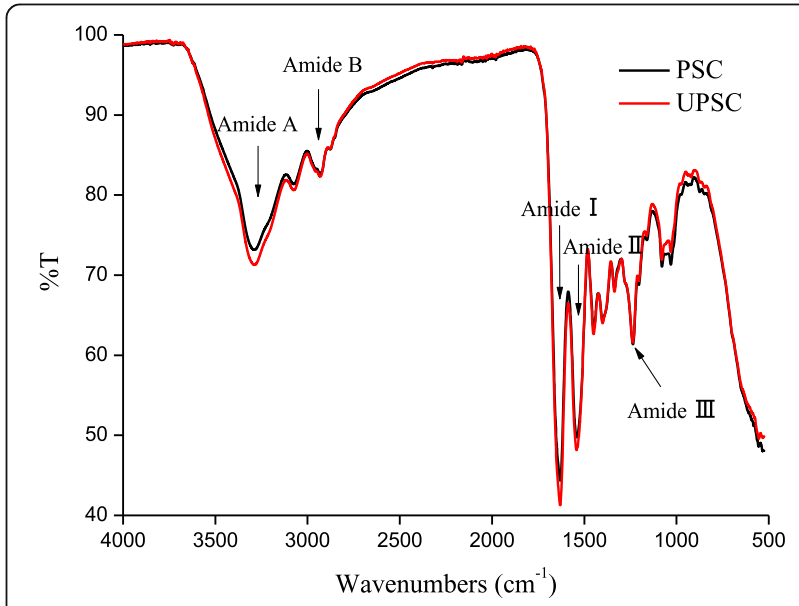

Fig. 3 Fourier transforms infrared spectra (FTIR) of PSC and UPSC from chicken lung 
wave numbers $\left(1237 \mathrm{~cm}^{-1}\right)$, and wave numbers were slightly lower than the collagen from Loligo vulgaris squid mantle $\left(1246 \mathrm{~cm}^{-1}\right)$ (Cozza et al. 2016). Therefore, partial telopeptides were eliminated by pepsin during collagen preparation, probably resulting in the remove of active amino acids in the telopeptide area of the PSC and UPSC molecules (Dalla Valle et al. 2013). Additionally, strong $\mathrm{C}-\mathrm{H}$ stretching at wave numbers of 1454 and $1452 \mathrm{~cm}^{-1}$ were observed for PSC and UPSC, respectively. This suggested that some differences existed between the secondary structural components between PSC and UPSC from chicken lung, but ultrasound pre-treatment had little effect on the triple-helical structure of collagen. In conclusion, the FTIR peak locations indicated that the inherent characteristics of PSC and UPSC were conserved.

\section{Amino acid composition}

The amino acid composition of PSC and UPSC are presented in Table 2. The compositions were similar to other collagens, in which glycine (Gly, 22.6\%) was a major component, followed by alanine (Ala) and proline (Pro). The results in this study were also in accordance

Table 2 Amino acid composition of PSC and UPSC from chicken lung $(\%, w / w)$

\begin{tabular}{lll}
\hline Amino acid & PSC & UPSC \\
\hline Asp & $5.71 \pm 0.13^{\mathrm{b}}$ & $4.87 \pm 0.11^{\mathrm{a}}$ \\
Glu & $10.92 \pm 0.21^{\mathrm{b}}$ & $10.35 \pm 0.19^{\mathrm{a}}$ \\
Ser & $3.98 \pm 0.09^{\mathrm{a}}$ & $3.74 \pm 0.12^{\mathrm{a}}$ \\
His & $0.90 \pm 0.04^{\mathrm{a}}$ & $0.86 \pm 0.03^{\mathrm{a}}$ \\
Gly & $22.27 \pm 0.25^{\mathrm{a}}$ & $22.58 \pm 0.24^{\mathrm{a}}$ \\
Thr & $2.61 \pm 0.07^{\mathrm{a}}$ & $3.07 \pm 0.12^{\mathrm{b}}$ \\
Arg & $7.39 \pm 0.14^{\mathrm{b}}$ & $6.47 \pm 0.16^{\mathrm{a}}$ \\
Ala & $11.87 \pm 0.20^{\mathrm{a}}$ & $12.75 \pm 0.21^{\mathrm{b}}$ \\
Pro & $10.72 \pm 0.16^{\mathrm{a}}$ & $11.31 \pm 0.12^{\mathrm{b}}$ \\
Hyp & $8.63 \pm 0.15^{\mathrm{a}}$ & $9.45 \pm 0.13^{\mathrm{b}}$ \\
Tyr & $0.011 \pm 0.0$ & - \\
Val & $2.52 \pm 0.05^{\mathrm{a}}$ & $2.96 \pm 0.10^{\mathrm{b}}$ \\
Met & $0.12 \pm 0.0^{\mathrm{a}}$ & $0.15 \pm 0.01^{\mathrm{b}}$ \\
Cys & - & - \\
Ile & $1.35 \pm 0.05^{\mathrm{a}}$ & $1.41 \pm 0.07^{\mathrm{a}}$ \\
Leu & $3.20 \pm 0.06^{\mathrm{a}}$ & $3.42 \pm 0.09^{\mathrm{b}}$ \\
Phe & $0.67 \pm 0.02^{\mathrm{a}}$ & $0.86 \pm 0.02^{\mathrm{b}}$ \\
Lys & $3.74 \pm 0.04^{\mathrm{a}}$ & $4.22 \pm 0.05^{\mathrm{b}}$ \\
Hydrophobic amino acids & $33.06 \pm 0.22^{\mathrm{a}}$ & $35.93 \pm 0.19^{\mathrm{b}}$ \\
Imino acid & $19.35 \pm 0.16^{\mathrm{a}}$ & $20.76 \pm 0.15^{\mathrm{b}}$ \\
\hline
\end{tabular}

\# Hydrophobic amino acids: Ala + Thr + Val + Pro + lle + Leu + Met + Phe ${ }^{*}$ Imino acid: Pro + Hyp

Different letters within the same line indicate significant difference; $P<0.05$ with those of Zhang et al. (2007) and Suleria et al. (2016), who also found that Gly was the most abundant amino acid in collagen. Ala was found as the major amino acid in the fins and scales of C. catla and C. mrigala. (Kittiphattanabawon et al. 2010). The contents of imino acids (proline and hydroxyproline, Pro and Hyp) of PSC and UPSC were 19.35 and 20.76\%, respectively, which were greater than those of collagen from grass carp skin (18.6\%) (Zhang et al. 2007). The imino acid contents in PSC and UPSC were also higher than those of skin collagens from cold-water fish, such as cod (15.4\%) (Giraud-Guille et al. 2000) and warmwater fish bighead carp (Hypophthalmichthys nobilis) and grass carp (Ctenopharyngodon idella) (17.0$18.0 \%)$ (Hu et al. 2016). Regions of collagen containing Hyp and Pro participate in the production of connections stabilized by a hydrogen bond (Kaewdang et al. 2014). Therefore, imino acid contents are very significant for the collagen structural integrity. Thr, Met, Ile, Tyr, Phe, and His, however, showed significant lower concentrations, and Cys and Trp were not detected at all because $\mathrm{HCl}$ destroys them and their quantification acquires other procedures. The differences between PSC and UPSC for amino acid composition were statistically significant $(P<0.05)$, thereby, indicating a qualitative difference in these collagen (Mahboob 2015). Helices of PSC might be less stable with a lower imino acid content compared with that of UPSC. Therefore, thermal properties of PSC and UPSC were subsequently determined.

\section{Viscosity and the denaturation temperature $\left(T_{d}\right)$}

The triple helix structure of collagen molecule can be transformed into an unordered coil construction by external cause, accompanied by reduction in viscosity values and solubility (Usha \& Ramasami 2004). Therefore, viscosity determinations are usually used during the thermo-stability study of macromolecules. As shown in Fig. 4, the fractional change of PSC and UPSC from chicken lung was lessened continually when the temperature increased in the range of $10-60^{\circ} \mathrm{C}$. Rising temperature could break hydrogen bonds of collagen, and transform trimers into individual chains or dimmers. Finally, this treatment results in a change in the collagen denaturation (Kiew \& Mashitah 2013). The $T_{d}$ of UPSC and PSC was 38.5 and $35.3^{\circ} \mathrm{C}$, respectively. These results might be due to the Hyp ratio while it was highly correlated with thermal stability of UPSC and PSC. Additionally, the present $T_{d}$ was obviously lower than that of mammalian collagen $\left(T_{d}\right.$ of $\sim 40^{\circ} \mathrm{C}$ ) (Yousefi et al. 2017). The variation in $T_{d}$ values might be due to the differences in species, body temperatures, living 


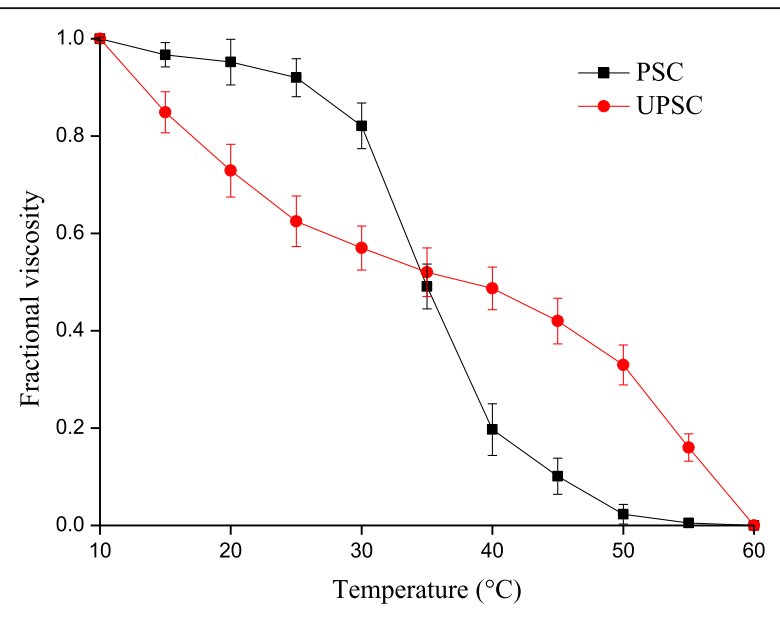

Fig. 4 Thermal denaturation curves of PSC and UPSC from chicken lung

conditions, and some differences in determination methods.

\section{Differential scanning calorimetry (DSC)}

The DSC pattern of PSC and UPSC is depicted in Fig. 5. The peak was related to continued conformational transformations of super-helix as a result of the destruction of materials. The $T_{m}$ of PSC and UPSC was 90.16 and $94.16^{\circ} \mathrm{C}$, respectively, and the $T_{d}$ (the above section) of UPSC was higher than that of PSC, consistent with the higher Hyp content of the UPSC (9.45\%) than PSC $(8.36 \%)$. The results indicated that thermal properties of collagens were related to their physicochemical changes caused by ultrasound treatment. They also demonstrated that ultrasound treatment partially alters the degrees of hydration, and the property of covalent cross-links. Hence, UPSC could have greater advantage in thermal

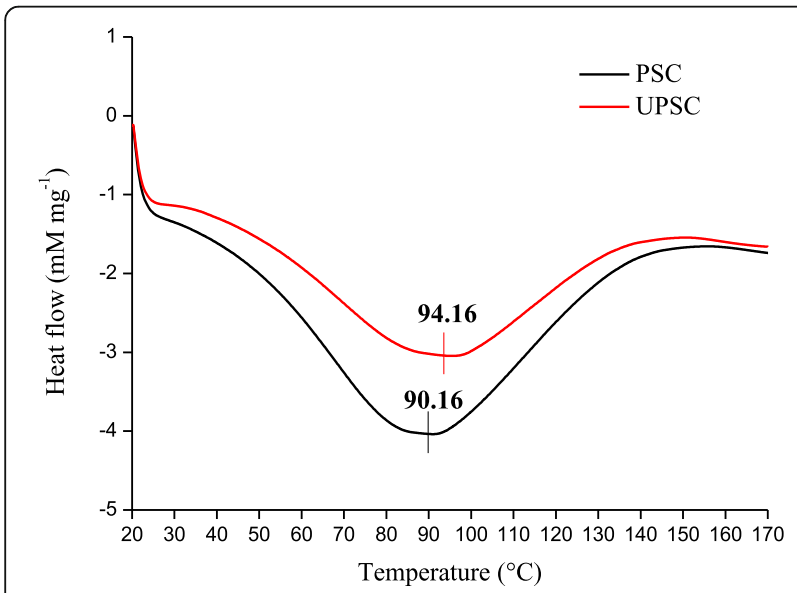

Fig. 5 Differential scanning calorimetry (DSC) thermograms of PSC and UPSC from chicken lung stability and is promising in food processing, cosmetics and other industries.

\section{Scanning electron microscopy (SEM)}

Lyophilized PSC and UPSC were in loose, fibrous, porous and multi-layered aggregated structures observed by SEM (Fig. 6), similar to collagens from skeletal bone collagen (SCII) and head bone collagen (HCII) (Jeevithan et al. 2014). However, UPSC exhibited a looser and larger aperture structure than PSC. Moderate and uniformly distributed pore size of collagen was suitable for in vivo studies in various applications (Caliari et al. 2011; Cheng et al. 2017). For the difference in pore diameter of the two collagens, the different appearance might be due to the mechanical action and cavitation effect by ultrasound treatment, and different collagen concentrations before lyophilization. The average pore diameter and porosity of collagen are extensively considered as critical factors for biomaterials (Song et al. 2006). Some researchers have also found that the surface microstructure can be altered on the basis of the collagen content during sample preparation (Ikoma et al. 2003; Tang et al. 2015). Thus, UPSC may serve as an alternative source of collagens for application in food packaging, processing, and biomedical industries.

\section{Solubility \\ Effect of $\mathrm{pH}$}

As shown in Fig. 7a, PSC and UPSC had a greater solubility in the acidic range of $\mathrm{pH} 1-4$, and maximums solubility at $\mathrm{pH} 3-4$. Denaturation of PSC and UPSC could occur to some extent under $\mathrm{pH} 1.0$, resulting in lower solubility. Sharp decrease in solubility was then observed by increasing the $\mathrm{pH}$ and a minimum was reached at $\mathrm{pH} 8$. Additionally, an increase in sample solubility was also presented in an alkali $\mathrm{pH}$ range. The reason for the higher relative solubility might be due to the greater net residue charges of collagen molecules, which improves inter-chain repulsion forces between chains, when the $\mathrm{pH}$ is higher or lower than the isoelectric point (pI) of collagen (Liu et al. 2012; Zhang et al. 2014). These results were similar to the study of Woo et al. (2008). In addition, UPSC exhibited higher solubilities than PSC in all tested $\mathrm{pH}$ range with the exception of $\mathrm{pH} 1-2$, which implied UPSC could reduce the degree of cross-linking or weaken bonds due to ultrasound treatment in comparison with PSC from chicken lung (Jongjareonrak et al. 2005; Li et al. 2013; Yu et al. 2014).

\section{Effect of $\mathrm{NaCl}$}

Both UPSC and PSC from chicken lung had similar solubility patterns in different $\mathrm{NaCl}$ concentrations (Fig. 7b). UPSC and PSC possessed better solubilities 

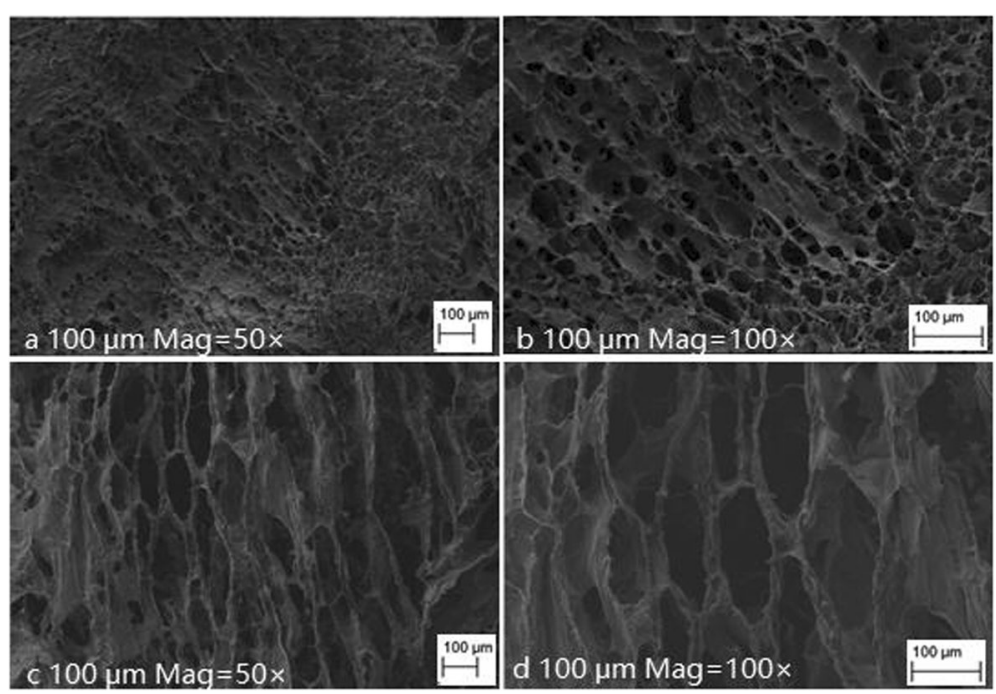

Fig. 6 Scanning electron microscopy (SEM) of collagen from chicken lung (a) PSC, Mag = 50 ; (b) PSC, Mag = $100 \times$; (c) UPSC, Mag = $50 \times$; (d) UPSC, Mag $=100 \times$
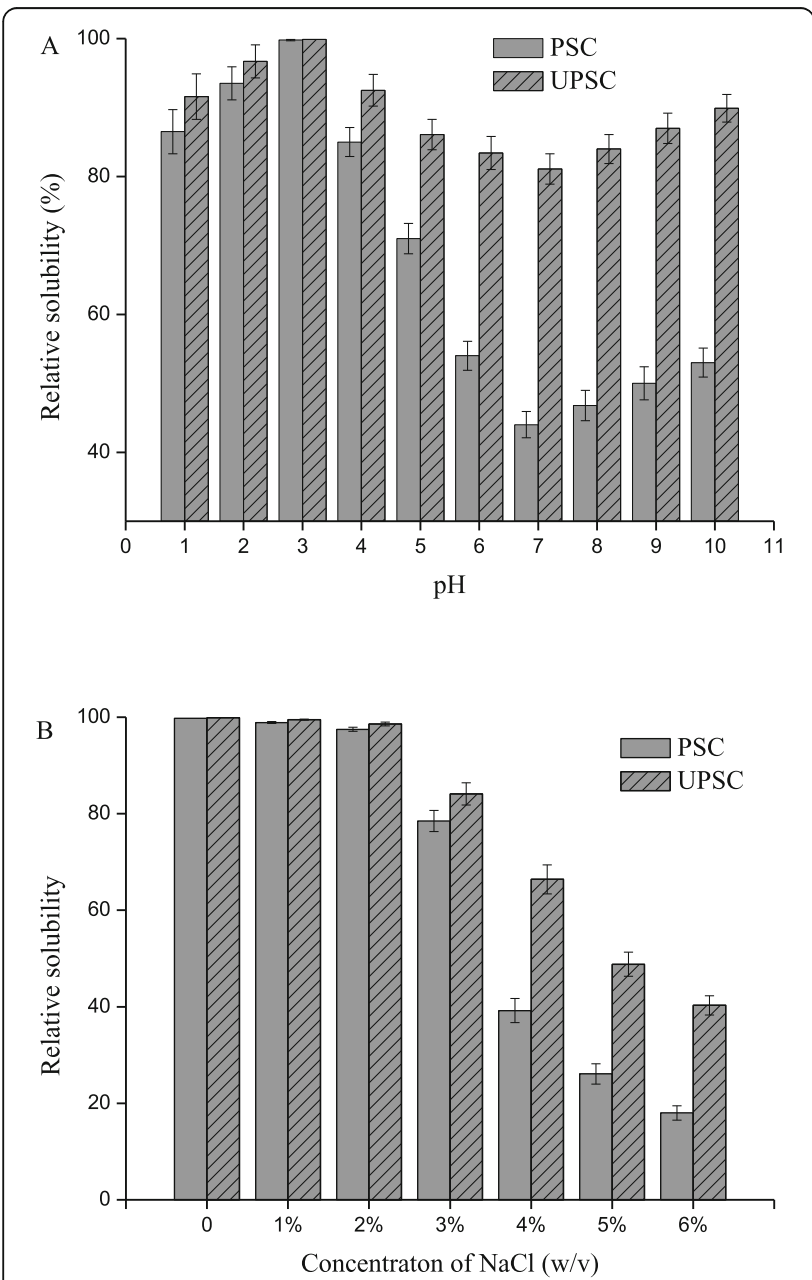

Fig. 7 Relative solubility (\%) of PSC and UPSC from chicken lung as affected by different environmental factors. $\mathbf{a} \mathrm{pH} ; \mathbf{b}$ concentration of $\mathrm{NaCl}$ at $\mathrm{NaCl}$ concentrations below $2 \%$, which was then significantly dropped when $\mathrm{NaCl}$ concentration was in the range of $3-6 \%$. The solubility trend was consistent with collagens from the skin of trout, brown stripe red snapper and Spanish mackerel (Jongjareonrak et al. 2005; Li et al. 2013). The increase in the competition with water for $\mathrm{NaCl}$ is known to contribute to enhancing hydrophobic interactions between protein chains and lead to more collagen precipitation, as the ionic strength increased (Minh Thuy et al. 2014). Moreover, UPSC presented higher solubilities than PSC at $\mathrm{NaCl}$ concentration above $2 \%$. This result showed that ultrasound treatment induced a partial hydrolysis of high molecular weight cross-linked collagen from pepsin extraction, leading to a higher solubility of UPSC from chicken lung.

\section{Protein profiles of collagen after ultrasound pre- treatment}

NanoLC-ESI MS/MS is a sensitive technique to identify the sequencing peptides, so it was used in our study. The spectra resulting from data-dependent acquisitions in the NCBI database by using Mascot scores of peptide identification were for the $\alpha-1$ and $\alpha-2$ bands in UPSC gel. Among the peaks, a charged peak with $\mathrm{m} / \mathrm{z}$ 835.4, 1505.8 and 811.4 was the main component in $\alpha-1$ and $\alpha-2$ band as determined by nanoLC-ESI MS/MS, and the sequencing peptide was identified as GPAGPQGPR, QLEEAEEESQR and GVAGPQGAR, respectively (Fig. 8). When this sequence was searched online in NCBI, we found a record of peptide from chick collagen alpha-2(I) chain [Gallus gallus] with 100\% identification. The stabilization of this conformation requires 


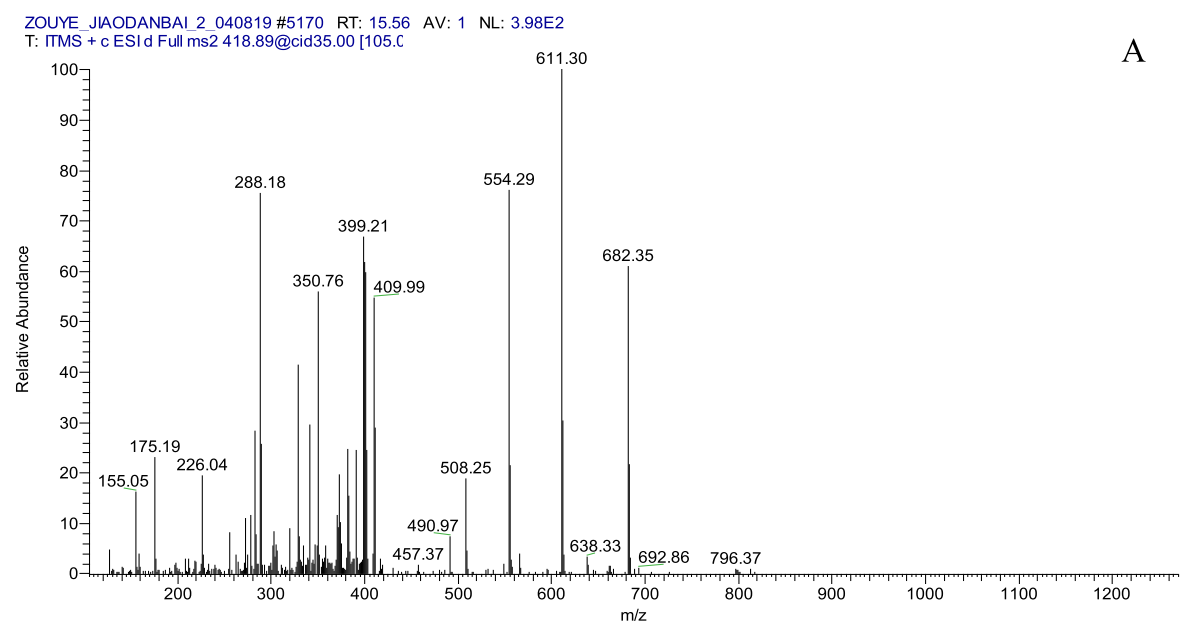

ZOUYE_JIAODANBAI 2 040819 \#5499 RT: 20.57 AV: 1 NL: 3.42E3

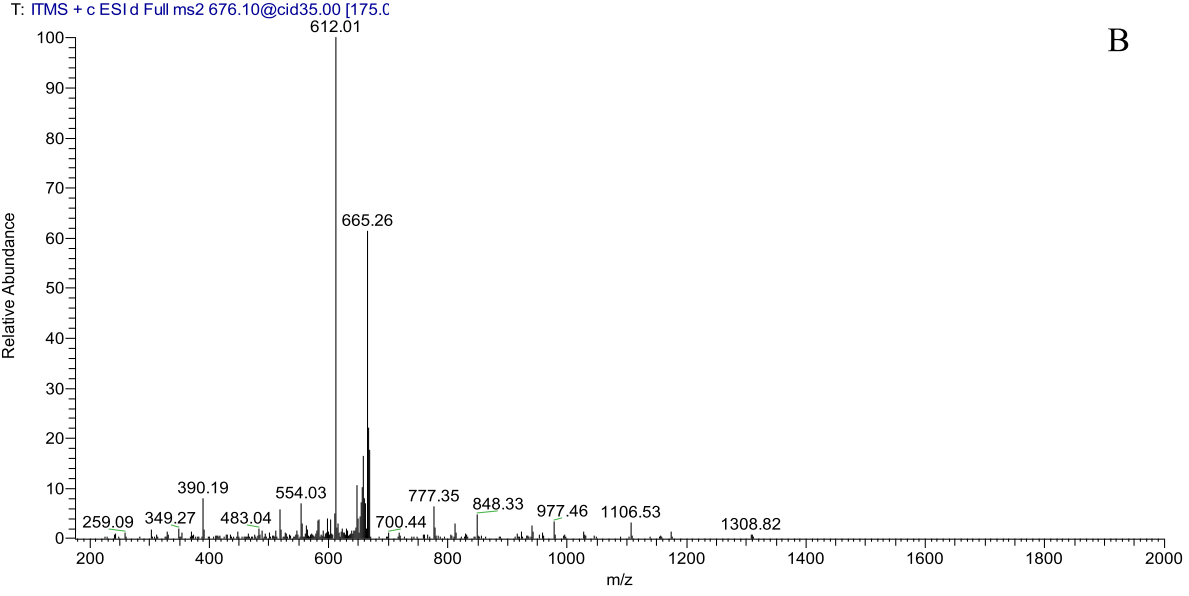

ZOUYE_JIAODANBAI 3 3040819 \#5180 RT: 15.72 AV: 1 NL: 1.06E3

T: ITMS

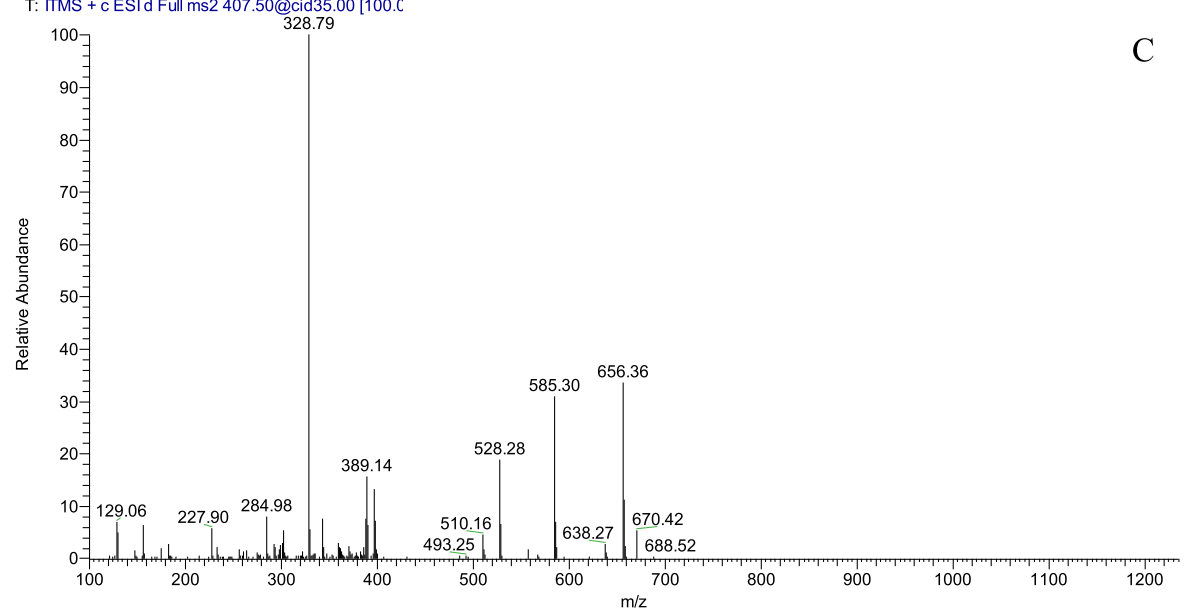

$\mathrm{C}$

Fig. 8 MS fingerprints of main collagen from chicken lung. Sequencing peptide: a GPAGPQGPR, b QLEEAEEESQR and (c) GVAGPQGAR, respectively

the presence of Gly residues at every third position in the sequence and high contents of imino acids. The collagens in proteomic analysis shown in Table 3 could be classified on the basis of their biological function. Briefly, UPSC from chicken lung is classified into 10 main groups, such as collagen alpha-2(I) chain (Fragments), chick actin, cytoplasmic 1 OS, etc. Based on the SDS-PAGE subunit, amino acid composition and peptide profiles, it might be concluded that collagen from chicken lung, is type II collagen. Therefore, the results 
Table 3 Identified UPSC from chicken lung sample by LC-ESI-MS/MS sequencing and analysis

\begin{tabular}{|c|c|c|c|c|}
\hline Collagen a-1 & Sequence Header & Protein mass & Protein count & Percentage (\%) \\
\hline & $\begin{array}{l}\text { >sp.|P02457|CO1A1_CHICK Collagen alpha-1(I) chain OS = Gallus gallus } \\
\text { GN=COL1A1 PE }=1 \text { SV = }\end{array}$ & $138,696.42$ & 4 & $45.3 \%$ \\
\hline & $\begin{array}{l}\text { >sp.|P10587|MYH11_CHICK Myosin-11 OS = Gallus gallus GN = MYH11 } \\
\mathrm{PE}=1 \mathrm{SV}=4\end{array}$ & $229,509.19$ & 14 & $40.7 \%$ \\
\hline & $\begin{array}{l}>\operatorname{tr} \mid \text { A0A1D5PGZ0|A0A1D5PGZ0_CHICK Uncharacterized protein } \\
\mathrm{OS}=\text { Gallus gallus PE }=4 \mathrm{SV}=1\end{array}$ & $48,263.92$ & 2 & $6.8 \%$ \\
\hline & $\begin{array}{l}\text { >sp.|P02467|CO1A2_CHICK Collagen alpha-2(I) chain (Fragments) } \\
\mathrm{OS}=\text { Gallus gallus GN=COL1A2 PE }=1 \mathrm{SV}=2\end{array}$ & $180,555.8$ & 12 & $2.1 \%$ \\
\hline & $\begin{array}{l}>\text { tr|A0A1D5PX03|A0A1D5PX03_CHICK Uncharacterized protein } \\
\text { OS }=\text { Gallus gallus PE }=4 \mathrm{SV}=1\end{array}$ & $95,230.95$ & 2 & $3.0 \%$ \\
\hline & $\begin{array}{l}\text { >sp.|P60706|ACTB_CHICK Actin, cytoplasmic } 1 \text { OS = Gallus gallus } \\
\mathrm{GN}=\mathrm{ACTB} P \mathrm{PE}=1 \mathrm{SV}=1\end{array}$ & $42,051.85$ & 1 & $2.1 \%$ \\
\hline \multirow[t]{4}{*}{ Collagen a-2 } & $\begin{array}{l}\text { >sp.|P02467|CO1A2_CHICK Collagen alpha-2(l) chain (Fragments) } \\
\text { OS = Gallus gallus GN=COL1A2 PE }=1 \mathrm{SV}=2\end{array}$ & $180,555.8$ & 41 & $83.5 \%$ \\
\hline & $\begin{array}{l}\text { >sp.|P02457|CO1A1_CHICK Collagen alpha-1(I) chain OS = Gallus } \\
\text { gallus GN=COL1A1 PE }=1 \mathrm{SV}=3\end{array}$ & $138,696.42$ & 17 & $12.8 \%$ \\
\hline & $\begin{array}{l}\text { >sp.|P10587|MYH11_CHICK Myosin-11 OS = Gallus gallus } \\
\mathrm{GN}=\mathrm{MYH} 11 \mathrm{PE}=1 \mathrm{SV}=4\end{array}$ & $229,509.19$ & 7 & $3.5 \%$ \\
\hline & $\begin{array}{l}\text { >sp.|P60706|ACTB_CHICK Actin, cytoplasmic } 1 \text { OS = Gallus } \\
\text { gallus GN }=\text { ACTB PE }=1 \mathrm{SV}=1\end{array}$ & $42,051.85$ & 1 & $0.1 \%$ \\
\hline
\end{tabular}

of protein profiles of UPSC could offer useful knowledge to better understand the collagen profile from chicken lung.

\section{Conclusion}

The chicken lung serves as an alternative source of collagen with a maximum collagen yield of $31.25 \%$ upon ultrasound pre-treatment at $150 \mathrm{~W}$ through the extraction kinetics. UPSC from chicken lung peptide was mainly identified as GPAGPQGPR, QLEEAEEESQR and GVAGPQGAR with a higher thermal stability, a better fibril forming capacity as well as better solubility in different $\mathrm{pH}$ and $\mathrm{NaCl}$ solution. Thus, UPSC from chicken lung serves as a potential alternative source of mammal collagens for applications in food processing, packaging and biomedical fields. The biological activity of peptides from chicken lung needs to be further studied.

\section{Abbreviations}

DSC: Differential scanning calorimetry; FT-IR: Fourier transform infrared; PSC: Pepsin-soluble collagen; SDS-PAGE: Sodium dodecyl sulfatepolyacrylamide gel electrophoresis; SEM: Scanning electron microscopy; $T_{d}$ : Denaturation temperature; UPSC: Pepsin-soluble collagen from ultrasound pretreated chicken lung

\section{Acknowledgements}

We thank the staffs of the Central Laboratory at Jiangsu Academy of Agricultural Sciences for their help in DSC and SEM analysis.

\section{Authors' contributions}

$Y Z$ designed this research, performed these experiments and wrote this manuscript; HY, XZ and MZ performed research; PX and DJ analyzed data; DW and WX conceived the study and exited the manuscript; and all authors read and approved the final article.

\section{Funding}

This study was supported by National Natural Science Foundation of China (31901612), China agriculture research system (CARS-41), Natural Science Foundation Program of Jiangsu Province (BK20180300), Agricultural science and technology innovation fund projects of Jiangsu Province (CX (18)1006), and Fundamental Research Funds for Jiangsu Academy of Agricultural Sciences (ZX (18)3009).

\section{Availability of data and materials}

This is a research manuscript and all datasets on which the conclusions of the manuscript rely are included in the tables of the manuscript.

Ethics approval and consent to participate

Not applicable.

\section{Consent for publication}

Not applicable.

\section{Competing interests}

The authors declare that they have no competing interests.

\section{Author details}

${ }^{1}$ Institute of Agricultural Products Processing, Jiangsu Academy of Agricultural Sciences, Nanjing 210014, People's Republic of China. ${ }^{2}$ Department of Enterprise Innovation, Jiangsu Science and Technology Development Strategy Research Institute, Nanjing 210042, People's Republic of China.

Received: 26 July 2019 Accepted: 18 December 2019 Published online: 20 January 2020

\section{References}

Alfaro, A. T., Biluca, F. C., Marquetti, C., Tonial, I. B., \& de Souza, N. E. (2014). African catfish (Clarias gariepinus) skin gelatin: Extraction optimization and physicalchemical properties. Food Research International, 65(Part C), 416-422.

Bhagwat, P. K., \& Dandge, P. B. (2016). Isolation, characterization and valorizable applications of fish scale collagen in food and agriculture industries. Biocatalysis and Agricultural Biotechnology, 7, 234-240.

Bucić-Kojić, A., Planinić, M., Tomas, S., Bilić, M., \& Velić, D. (2007). Study of solidliquid extraction kinetics of total polyphenols from grape seeds. Journal of Food Engineering, 81, 236-242. 
Caliari, S. R., Ramirez, M. A., \& Harley, B. A. C. (2011). The development of collagen-GAG scaffold-membrane composites for tendon tissue engineering. Biomaterial., 32, 8990-8998.

Chen, S., Chen, H., Xie, Q., Hong, B., Chen, J., Hua, F., Bai, K., He, J., Yi, R., \& Wu, H. (2016). Rapid isolation of high purity pepsin-soluble type I collagen from scales of red drum fish (Sciaenops ocellatus). Food Hydrocolloids, 52, 468-477.

Cheng, K.-Y., Chang, C.-H., Yang, Y.-W., Liao, G.-C., Liu, C.-T., \& Wu, J.-S. (2017). Enhancement of cell growth on honeycomb-structured polylactide surface using atmospheric-pressure plasma jet modification. Applied Surface Science, 394, 534-542.

Chuaychan, S., Benjakul, S., \& Kishimura, H. (2015). Characteristics of acid- and pepsin-soluble collagens from scale of seabass (Lates calcarifer). LWT- Food Science and Technology, 63, 71-76.

Cozza, N., Bonani, W., Motta, A., \& Migliaresi, C. (2016). Evaluation of alternative sources of collagen fractions from Loligo vulgaris squid mantle. International Journal of Biological Macromolecules, 87, 504-513.

Dahmoune, F., Spigno, G., Moussi, K., Remini, H., Cherbal, A., \& Madani, K. (2014). Pistacia lentiscus leaves as a source of phenolic compounds: Microwave-assisted extraction optimized and compared with ultrasoundassisted and conventional solvent extraction. Industrial Crops and Products, 61, 31-40.

Dalla Valle, L., Michieli, F., Benato, F., Skobo, T., \& Alibardi, L. (2013). Molecular characterization of alpha-keratins in comparison to associated beta-proteins in soft-shelled and hard-shelled turtles produced during the process of epidermal differentiation. The Journal of Experimental Zoology Part. B., 320, 428-441.

FAO. (2018). FAOSTAT domainshttp://faostat3.fao.org/faostat-gateway/go/to/download/Q/QL/E. Food and Agriculture organization of the United Nations.

Giraud-Guille, M.-M., Besseau, L., Chopin, C., Durand, P., \& Herbage, D. (2000). Structural aspects of fish skin collagen which forms ordered arrays via liquid crystalline states. Biomaterial., 21, 899-906.

Ho, Y.-S., Harouna-Oumarou, H. A., Fauduet, H., \& Porte, C. (2005). Kinetics and model building of leaching of water-soluble compounds of Tilia sapwood. Separation and Purification Technology, 45, 169-173.

Hu, J., Li, T., Liu, X., \& Liu, D. (2016). Seasonal variation of acid-soluble collagens extracted from the swim bladders and skins of bighead carp (Hypophthalmichthys nobilis) and grass carp (Ctenopharyngodon idella). Food Bioscience, 15, 27-33

Huang, C.-Y., Kuo, J.-M., Wu, S.-J., \& Tsai, H.-T. (2016). Isolation and characterization of fish scale collagen from tilapia (Oreochromis sp.) by a novel extrusionhydro-extraction process. Food Chemistry, 190, 997-1006.

Ikoma, T., Kobayashi, H., Tanaka, J., Walsh, D., \& Mann, S. (2003). Physical properties of type I collagen extracted from fish scales of Pagrus major and Oreochromis niloticas. International Journal of Biological Macromolecules, 32, 199-204.

Jana, P., Mitra, T., Selvaraj, T. K. R., Gnanamani, A., \& Kundu, P. P. (2016). Preparation of guar gum scaffold film grafted with ethylenediamine and fish scale collagen, cross-linked with ceftazidime for wound healing application. Carbohydrate Polymers, 153, 573-581.

Jeevithan, E., Wu, W., Nanping, W., Lan, H., \& Bao, B. (2014). Isolation, purification and characterization of pepsin soluble collagen isolated from silvertip shark (Carcharhinus albimarginatus) skeletal and head bone. Process Biochemistry, 49, 1767-1777

Jongjareonrak, A., Benjakul, S., Visessanguan, W., Nagai, T., \& Tanaka, M. (2005). Isolation and characterisation of acid and pepsin-solubilised collagens from the skin of Brownstripe red snapper (Lutjanus vitta). Food Chemistry, 93, 475-484.

Kaewdang, O., Benjakul, S., Kaewmanee, T., \& Kishimura, H. (2014). Characteristics of collagens from the swim bladders of yellowfin tuna (Thunnus albacares). Food Chemistry, 155, 264-270.

Kang, D.-C., Gao, X.-Q., Ge, Q.-F., Zhou, G.-H., \& Zhang, W.-G. (2017). Effects of ultrasound on the beef structure and water distribution during curing through protein degradation and modification. Ultrasonics Sonochemistry, 38, 317-325.

Kiew, P. L., \& Mashitah, M. D. (2013). Isolation and characterization of collagen from the skin of Malaysian catfish (hybrid Clarias sp.). Journal of the Korean Society for Applied Biological Chemistry, 56, 441-450.

Kittiphattanabawon, P., Benjakul, S., Visessanguan, W., \& Shahidi, F. (2010). Isolation and characterization of collagen from the cartilages of brownbanded bamboo shark (Chiloscyllium punctatum) and blacktip shark (Carcharhinus limbatus). LWT- Food Science and Technology, 43, 792-800.

Kobayashi, Y., Kuriyama, T., Nakagawara, R., Aihara, M., \& Hamada-Sato, N. (2016). Allergy to fish collagen: Thermostability of collagen and IgE reactivity of patients' sera with extracts of 11 species of bony and cartilaginous fish. Allergology International, 65, 450-458.

Li, Z.-R., Wang, B., Chi, C.-f., Zhang, Q.-H., Gong, Y.-d., Tang, J.-J., Luo, H.-y., \& Ding, G.-f. (2013). Isolation and characterization of acid soluble collagens and pepsin soluble collagens from the skin and bone of Spanish mackerel (Scomberomorous niphonius). Food Hydrocolloids, 31, 103-113.

Liu, D., Liang, L., Regenstein, J. M., \& Zhou, P. (2012). Extraction and characterisation of pepsin-solubilised collagen from fins, scales, skins, bones and swim bladders of bighead carp (Hypophthalmichthys nobilis). Food Chemistry, 133, 1441-1448.

Mahboob, S. (2015). Isolation and characterization of collagen from fish waste material- skin, scales and fins of Catla catla and Cirrhinus mrigala. Journal of Food Science and Technology, 52, 4296-4305.

Minh Thuy, L. T., Okazaki, E., \& Osako, K. (2014). Isolation and characterization of acid-soluble collagen from the scales of marine fishes from Japan and Vietnam. Food Chemistry, 149, 264-270.

Oechsle, A. M., Akgün, D., Krause, F., Maier, C., Gibis, M., Kohlus, R., \& Weiss, J. (2016). Microstructure and physical-chemical properties of chicken collagen. Food Structure, 7, 29-37.

Pal, G. K., Nidheesh, T., \& Suresh, P. V. (2015). Comparative study on characteristics and in vitro fibril formation ability of acid and pepsin soluble collagen from the skin of catla (Catla catla) and rohu (Labeo rohita). Food Research International, 76(Part 3), 804-812.

Pal, G. K., \& Suresh, P. V. (2016). Sustainable valorisation of seafood by-products: Recovery of collagen and development of collagen-based novel functional food ingredients. Innovative food science \& emerging technologies, 37(Part B) 201-215.

Petibois, C., \& Déléris, G. (2006). Chemical mapping of tumor progression by FT-IR imaging: Towards molecular histopathology. Trends in Biotechnology, 24, 455462

Peticolas, W. L. (1979). Low frequency vibrations and the dynamics of proteins and polypeptides. Methods in enzymology, 61, 425-458.

Qu, W., Pan, Z., \& Ma, H. (2010). Extraction modeling and activities of antioxidants from pomegranate marc. Journal of Food Engineering, 99, 16-23.

Saavedra, J., Córdova, A., Gálvez, L., Quezada, C., \& Navarro, R. (2013). Principal component analysis as an exploration tool for kinetic modeling of food quality: A case study of a dried apple cluster snack. Journal of Food Engineering, 119, 229-235.

Song, E., Yeon Kim, S., Chun, T., Byun, H.-J., \& Lee, Y. M. (2006). Collagen scaffolds derived from a marine source and their biocompatibility. Biomaterial., 27, $2951-2961$.

Suleria, H. A. R., Gobe, G., Masci, P., \& Osborne, S. A. (2016). Marine bioactive compounds and health promoting perspectives; innovation pathways for drug discovery. Trends in Food Science and Technology, 50, 44-55.

Tang, L., Chen, S., Su, W., Weng, W., Osako, K., \& Tanaka, M. (2015). Physicochemical properties and film-forming ability of fish skin collagen extracted from different freshwater species. Process Biochemistry, 50, 148-155.

Tao, Y., Zhang, Z., \& Sun, D.-W. (2014). Kinetic modeling of ultrasound-assisted extraction of phenolic compounds from grape marc: Influence of acoustic energy density and temperature. Ultrasonics Sonochemistry, 21, 1461-1469.

Usha, R., \& Ramasami, T. (2004). The effects of urea and n-propanol on collagen denaturation: Using DSC, circular dicroism and viscosity. Thermochimica Acta, 409, 201-206.

Wang, L., Liang, Q., Chen, T., Wang, Z., Xu, J., \& Ma, H. (2014). Characterization of collagen from the skin of Amur sturgeon (Acipenser schrenckii). Food Hydrocolloids, 38, 104-109.

Woo, J.-W., Yu, S.-J., Cho, S.-M., Lee, Y.-B., \& Kim, S.-B. (2008). Extraction optimization and properties of collagen from yellowfin tuna (Thunnus albacares) dorsal skin. Food Hydrocolloids, 22, 879-887.

Yang, Y. n., Li, C., Song, W., Wang, W., \& Qian, G. (2016). Purification, optimization and physicochemical properties of collagen from soft-shelled turtle calipash. International Journal of Biological Macromolecules, 89, 344-352.

Yousefi, M., Ariffin, F., \& Huda, N. (2017). An alternative source of type I collagen based on by-product with higher thermal stability. Food Hydrocolloids, 63, 372-382.

Yu, D., Chi, C.-F., Wang, B., Ding, G.-F., \& Li, Z.-R. (2014). Characterization of acidand pepsin-soluble collagens from spines and skulls of skipjack tuna (Katsuwonus pelamis). Chinese Journal of Natural Medicines, 12, 712-720.

Zhang, J., Duan, R., Huang, L., Song, Y., \& Regenstein, J. M. (2014). Characterisation of acid-soluble and pepsin-solubilised collagen from jellyfish (Cyanea nozakii Kishinouye). Food Chemistry, 150, 22-26. 
Zhang, Y., Liu, W., Li, G., Shi, B., Miao, Y., \& Wu, X. (2007). Isolation and partial characterization of pepsin-soluble collagen from the skin of grass carp (Ctenopharyngodon idella). Food Chemistry, 103, 906-912.

Zou, Y., Li, P., Zhang, K., Wang, L., Zhang, M., Sun, Z., Sun, C., Geng, Z., Xu, W., \& Wang, D. (2017). Effects of ultrasound-assisted alkaline extraction on the physiochemical and functional characteristics of chicken liver protein isolate Poultry Science, 96, 2975-2985.

\section{Publisher's Note}

Springer Nature remains neutral with regard to jurisdictional claims in published maps and institutional affiliations.

Ready to submit your research? Choose BMC and benefit from:

- fast, convenient online submission

- thorough peer review by experienced researchers in your field

- rapid publication on acceptance

- support for research data, including large and complex data types

- gold Open Access which fosters wider collaboration and increased citations

- maximum visibility for your research: over $100 \mathrm{M}$ website views per year

At $B M C$, research is always in progress. 